\title{
ОСОБЕННОСТИ СОМАТОВЕГЕТАТИВНЫХ ПРОЯВЛЕНИЙ У СТУДЕНЧЕСКОЙ МОЛОДЕЖИ С РАССТРОЙСТВОМ АДАПТАЦИИ, СКЛОННЫХ К УВЛЕЧЕНИЮ КОМПЬЮТЕРАМИ И СЕТЬЮ ИНТЕРНЕТ
}

По результатам отечественных и зарубежных исследований, частота выявления расстройств адаптации у различных слоев населения варьирует от $11-18 \%$ до $10-35 \%$. У студентов, по научным данным, расстройства адаптации определяются в $14-21 \%$ случаев $[1,2]$, что связано с высоким уровнем нагрузки первых лет обучения и трудностями психосоциальной адаптации в новой микросоциальной среде и учебновоспитательном пространстве вуза, а также с изменениями во внутрисемейном функционировании и отрывом от семьи.

В свою очередь психоадаптационные нарушения и расстройства оказывают выраженное негативное влияние на качество жизни, приводят к снижению эффективности образовательной деятельности, сопровождаются формированием диссонантных отношений с окружающими, повышают риск употребления психоактивных веществ (ПАВ) и нехимических аддикций, а также суицидов в студенческой среде [3, 4].

Общепризнано, что студенческий период характеризуется высокой восприимчивостью к манифестации и развитию психических заболеваний, разнообразных состояний психологической декомпенсации [5-10], что вызывает поиск средств снятия психоэмоционального напряжения и приводит к формированию различных стратегий преодоления стрессорных воздействий (копинга), чаще с применением ПАВ и увлеченностью компьютерами и сетью Интернет. Прогрессирующее распространение аддиктивного поведения у молодежи, негативным образом влияя на здоровье, является острой и актуальной медико-социальной проблемой современного общества, что обусловило наше исследование.

\section{ЦЕЛ В РАБОТ Ы}

Оценить соматовегетативные проявления у студенческой молодежи с расстройством адаптации, склонной к увлечению компьютерами и сетью Интернет.

\section{МАТЕРИАЛ И МЕТОДЫ}

Обследовали 510 студентов мужского и женского пола 1 и 2 курсов одного из университетов в возрасте от 17 до 20 лет.

Обследование проводили с соблюдением принципов деонтологии и биоэтики на условиях информированного согласия. Опрос проводили с использованием разработанной унифицированной «Карты обследования студента». Определяли, какое количество времени студенты проводят в сети Интернет и за компьютером.

Для оценки психоэмоционального состояния использовали тест SCL-90-R [11]. Оценивали взаимосвязь количества времени, проводимого в сети Интернет, с уровнем выраженности соматовегетативной симптоматики с использованием субшкалы соматизации (SOM) из опросника SCL-90-R.

Полученные данные заносили в таблицы Excel. Для статистической обработки пользовались пакетом программ «STATISTICA 10.0» .

На основании первичных данных были рассчитаны доли (Р, в \%), ошибки репрезентативности долей (m) и 95\% доверительные интервалы (95\% ДИ), в том числе рассчитывали показатели описательной статистики: средние арифметические величин (М), стандартные отклонения (sd), медианы (Me), минимумы (min) и максимумы (max) переменных. Формат представления данных по тексту и в таблицах следующий: $\mathrm{M}^{ \pm} \mathrm{sd}$ (min-max) $\mathrm{Me}=$. Для оценки значимости различий параметров распределения переменных в группах использовали непараметрический критерий множественных сравнений Крускала-Уоллиса.

\section{РЕЗУЛЬТАТЫ И ОБСУЖДЕНИЕ}

Выраженность психопатологической симптоматики определяли по шкале SCL-90-R. Дизайн

(c) О.А. Бешуля, 2020

(c) Университетская Клиника, 2020 
Показатели выраженности психопатологической симптоматики

Таблица 1. у студентов младших курсов университета по методике SCL-90-R, в баллах $(\mathrm{n}=510)$

\begin{tabular}{|c|c|c|c|c|c|c|}
\hline \multirow[t]{2}{*}{ Шкала } & \multicolumn{2}{|c|}{ Группа 1 , n=273 } & \multicolumn{2}{|c|}{ Группа 2, n=155 } & \multicolumn{2}{|c|}{ Группа 3, n=82 } \\
\hline & $\begin{array}{c}\text { женщины, } \\
\text { n=143 }\end{array}$ & $\begin{array}{c}\text { мужчины, } \\
\text { n=130 }\end{array}$ & $\begin{array}{c}\text { женщины, } \\
\text { n=95 }\end{array}$ & $\begin{array}{c}\text { мужчины, } \\
\text { n=60 }\end{array}$ & $\begin{array}{c}\text { женщины, } \\
\text { n=69 }\end{array}$ & $\begin{array}{c}\text { мужчины, } \\
\text { n=13 }\end{array}$ \\
\hline SOM & $\begin{array}{c}0,47 \pm 0,34 \\
(0,0-1,83) \\
\mathrm{Me}=0,42\end{array}$ & $\begin{array}{c}0,26 \pm 0,23 \\
(0,0-1,17) \\
\mathrm{Me}=0,17\end{array}$ & $\begin{array}{c}1,01 \pm 0,52 \\
(0,0-2,83) \\
M e=0,42\end{array}$ & $\begin{array}{c}0,82 \pm 0,41 \\
(0,0-1,67) \\
\mathrm{Me}=0,75\end{array}$ & $\begin{array}{c}1,94 \pm 0,71 \\
(0,5-3,75) \\
M e=1,83\end{array}$ & $\begin{array}{c}2,01 \pm 0,58 \\
(0,92-2,75) \\
M e=2,08\end{array}$ \\
\hline INT & $\begin{array}{c}0,44 \pm 0,31 \\
(0,0-1,44) \\
\mathrm{Me}=0,44\end{array}$ & $\begin{array}{c}0,32 \pm 0,30 \\
(0,0-1,33) \\
\mathrm{Me}=0,22\end{array}$ & $\begin{array}{c}1,33 \pm 0,53 \\
(0,33-2,89) \\
\mathrm{Me}=1,22\end{array}$ & $\begin{array}{c}1,32 \pm 0,49 \\
(0,44-2,44) \\
\mathrm{Me}=1,22\end{array}$ & $\begin{array}{c}2,22 \pm 0,67 \\
(0,89-3,78) \\
M e=2,22\end{array}$ & $\begin{array}{c}1,97 \pm 0,29 \\
(1,22-2,33) \\
M e=2,00\end{array}$ \\
\hline DEP & $\begin{array}{c}0,34 \pm 0,25 \\
(0,0-1,15) \\
\mathrm{Me}=0,31\end{array}$ & $\begin{array}{c}0,24 \pm 0,23 \\
(0,0-1,08) \\
\mathrm{Me}=0,15\end{array}$ & $\begin{array}{c}1,13 \pm 0,43 \\
(0,31-2,46) \\
\mathrm{Me}=1,08\end{array}$ & $\begin{array}{c}1,11 \pm 0,51 \\
(0,23-2,54) \\
\mathrm{Me}=1,00\end{array}$ & $\begin{array}{c}2,26 \pm 0,57 \\
(1,46-3,85) \\
\mathrm{Me}=2,15\end{array}$ & $\begin{array}{c}2,02 \pm 0,37 \\
(1,38-2,85) \\
\mathrm{Me}=2,00\end{array}$ \\
\hline ANX & $\begin{array}{c}0,29 \pm 0,22 \\
(0,0-1,10) \\
\mathrm{Me}=0,30\end{array}$ & $\begin{array}{c}0,19 \pm 0,21 \\
(0,0-1,30) \\
\mathrm{Me}=0,10\end{array}$ & $\begin{array}{c}0,89 \pm 0,40 \\
(0,10-1,90) \\
\mathrm{Me}=0,90\end{array}$ & $\begin{array}{c}0,91 \pm 0,42 \\
(0,0-2,00) \\
\mathrm{Me}=0,90\end{array}$ & $\begin{array}{c}2,08 \pm 0,64 \\
(0,70-3,80) \\
\mathrm{Me}=2,00\end{array}$ & $\begin{array}{c}2,03 \pm 0,31 \\
(1,50-2,70) \\
M e=2,00\end{array}$ \\
\hline РНOB & $\begin{array}{c}0,15 \pm 0,20 \\
(0,0-1,14) \\
\mathrm{Me}=0,14\end{array}$ & $\begin{array}{c}0,06 \pm 0,12 \\
(0,0-0,57) \\
\mathrm{Me}=0,00\end{array}$ & $\begin{array}{c}0,57 \pm 0,42 \\
(0,0-2,00) \\
\mathrm{Me}=0,43\end{array}$ & $\begin{array}{c}0,60 \pm 0,41 \\
(0,0-1,57) \\
\mathrm{Me}=0,50\end{array}$ & $\begin{array}{c}1,51 \pm 0,72 \\
(0,0-3,57) \\
\mathrm{Me}=1,43\end{array}$ & $\begin{array}{c}1,31 \pm 0,63 \\
(0,43-2,29) \\
\mathrm{Me}=1,14\end{array}$ \\
\hline
\end{tabular}

исследования предполагал разделение студентов на 3 группы: практически здоровые, с непатологическими нарушениями адаптации (ННА), с отдельными признаками расстройств адаптации (ОПРА). Для этого использовали кластерный анализ методом «k-срединных», с использованием субшкал SCL-90-R: SOM; INT; DEP; ANX; PHOB. В результате кластерного анализа получили следующие группы студентов: практически здоровые - 273 (53,5\%) студента, среди них 130 (47,6\%) человек мужского пола и 143 (52,4\%) - женского; с непатологическими нарушениями адаптации - 155 (30,4\%) человек, среди них 60 $(38,7 \%)$ лиц мужского пола и 95 (61,3\%) - женского; с отдельными признаками расстройств адаптации - 82 (16,1\%) человека, среди них 13 $(15,9 \%)$ мужского пола и $69(84,1 \%)$ - женского. Эти группы статистически значимо различают- ся по средним величинам вышеперечисленных субшкал SCL-90-R (табл. 1.).

Далее определяли частоту (в \%) ответов студентов на вопрос: «Сколько часов в день Вы обычно проводите за компьютером (отправляете сообщения по электронной почте, общаетесь Вконтакте, исследуете сеть и т.д.), не считая времени, которое Вы тратите на компьютерные игры?». Данный вопрос был включен в анкету с целью изучения увлеченности компьютерами и сетью Интернет. Результаты приведены в таблицах 2 и 3.

Согласно данным, представленным в таблице 2, большинство (41,5\%) практически здоровых студентов мужского пола проводит за компьютером в будние дни приблизительно 1-2 часа, в то же время студентки женского пола этой группы преимущественно (38,5\%) проводят за компьютером больше 2-х часов в день. В группе с

Таблица 2.

Распределение частоты ответов студентов на вопрос: «Сколько часов в день Вы обычно проводите за компьютером (отправляете сообщение по электронной почте, общаетесь Вконтакте, исследуете сеть и т.д.), не считая времени, которое Вы тратите на компьютерные игры?» (в будние дни)

\begin{tabular}{|c|c|c|c|c|c|c|}
\hline \multirow{2}{*}{ Вариант ответа } & \multicolumn{2}{|c|}{ Группа 1, n=273 } & \multicolumn{2}{|c|}{ Группа 2, n=155 } & \multicolumn{2}{|c|}{ Группа 3, n=82 } \\
\hline & M & Ж & M & ж & M & ж \\
\hline Нисколько & $\begin{array}{c}13 / 10,0 \pm 2,6 \\
(4,8-15,2)\end{array}$ & $\begin{array}{c}15 / 10,5 \pm 2,6 \\
(5,5-15,5)\end{array}$ & $\begin{array}{l}9 / 15,0 \pm 4,6 \\
(6,0-24,0)\end{array}$ & $\begin{array}{c}10 / 10,5 \pm 3,1 \\
(4,4-16,7) \\
\end{array}$ & 2 & $\begin{array}{c}11 / 15,9 \pm 4,4 \\
(7,3-24,6)\end{array}$ \\
\hline $\begin{array}{l}\text { Приблизительно } \\
\text { 1-2 часа в день }\end{array}$ & $\begin{array}{l}54 / 41,5 \pm 4,3 \\
(33,1-50,0)\end{array}$ & $\begin{array}{l}39 / 27,3 \pm 3,7 \\
(20,0-34,6)\end{array}$ & $\begin{array}{l}18 / 30,0 \pm 5,9 \\
(18,4-41,6)\end{array}$ & $\begin{array}{c}23 / 24,2 \pm 4,4 \\
(15,6-32,8)\end{array}$ & 7 & $\begin{array}{c}10 / 14,5 \pm 4,2 \\
(6,2-22,8)\end{array}$ \\
\hline Больше 2-х часов в день & $\begin{array}{c}39 / 30,0 \pm 4,0 \\
(22,1-37,9)\end{array}$ & $\begin{array}{l}55 / 38,5 \pm 4,1 \\
(30,5-46,4)\end{array}$ & $\begin{array}{c}22 / 36,7 \pm 6,2 \\
(24,5-48,9)\end{array}$ & $\begin{array}{l}41 / 43,2 \pm 5,1 \\
(33,2-53,1)\end{array}$ & 2 & $\begin{array}{l}19 / 27,5 \pm 5,4 \\
(17,0-38,1)\end{array}$ \\
\hline Примерно 5 часов в день & $\begin{array}{c}24 / 18,5 \pm 3,4 \\
(11,8-25,1)\end{array}$ & $\begin{array}{l}34 / 23,8 \pm 3,6 \\
(16,8-30,8)\end{array}$ & $\begin{array}{c}11 / 18,3 \pm 5,0 \\
(8,5-28,1)\end{array}$ & $\begin{array}{l}21 / 22,1 \pm 4,3 \\
(13,8-30,4)\end{array}$ & 2 & $\begin{array}{c}29 / 42,0 \pm 5,9 \\
(30,4-53,7)\end{array}$ \\
\hline
\end{tabular}


Таблица 3.

Распределение частоты ответов студентов на вопрос: «Сколько часов в день Вы обычно проводите за компьютером (отправляете сообщение по электронной почте, общаетесь Вконтакте, исследуете сеть и т.д.), не считая времени, которое Вы тратите на компьютерные игры?» (в выходные дни)

\begin{tabular}{|c|c|c|c|c|c|c|}
\hline \multirow{2}{*}{ Вариант ответа } & \multicolumn{2}{|c|}{ Группа 1, n=273 } & \multicolumn{2}{|c|}{ Группа 2, n=155 } & \multicolumn{2}{|c|}{ Группа 3, n=82 } \\
\hline & M & ж & M & ж & M & ж \\
\hline Нисколько & $\begin{array}{l}5 / 3,8 \pm 1,7 \\
(0,5-7,2)\end{array}$ & $\begin{array}{l}12 / 8,4 \pm 2,3 \\
(3,8-12,9)\end{array}$ & $\begin{array}{l}4 / 6,7 \pm 3,2 \\
(0,4-13,0)\end{array}$ & $\begin{array}{l}8 / 8,4 \pm 2,8 \\
(2,8-14,0)\end{array}$ & 2 & $\begin{array}{c}3 / 4,3 \pm 2,5 \\
(0-9,2)\end{array}$ \\
\hline $\begin{array}{l}\text { Приблизительно } \\
1-2 \text { часа в день }\end{array}$ & $\begin{array}{l}37 / 28,5 \pm 4,0 \\
(20,7-36,2)\end{array}$ & $\begin{array}{c}17 / 11,9 \pm 2,7 \\
(6,6-17,2)\end{array}$ & $\begin{array}{l}14 / 23,3 \pm 5,5 \\
(12,6-34,0)\end{array}$ & $\begin{array}{c}16 / 16,8 \pm 3,8 \\
(9,3-24,4)\end{array}$ & 3 & $\begin{array}{c}8 / 11,6 \pm 3,9 \\
(4,0-19,1)\end{array}$ \\
\hline Больше 2-х часов в день & $\begin{array}{l}62 / 47,7 \pm 4,4 \\
(39,1-56,3)\end{array}$ & $\begin{array}{l}67 / 46,9 \pm 4,2 \\
(38,7-55,0)\end{array}$ & $\begin{array}{l}20 / 33,3 \pm 6,1 \\
(21,4-45,3)\end{array}$ & $\begin{array}{l}33 / 34,7 \pm 4,9 \\
(24,2-44,3)\end{array}$ & 4 & $\begin{array}{l}23 / 33,3 \pm 5,7 \\
(22,2-44,5)\end{array}$ \\
\hline Примерно 5 часов в день & $\begin{array}{l}26 / 20,0 \pm 3,5 \\
(13,1-26,9)\end{array}$ & $\begin{array}{l}47 / 32,9 \pm 3,9 \\
(25,2-40,6)\end{array}$ & $\begin{array}{l}22 / 36,7 \pm 6,2 \\
(24,5-48,9)\end{array}$ & $\begin{array}{l}38 / 40,0 \pm 5,0 \\
(30,1-49,9)\end{array}$ & 4 & $\begin{array}{l}35 / 50,7 \pm 6,0 \\
(38,9-62,5)\end{array}$ \\
\hline
\end{tabular}

непатологическими нарушениями адаптации большая доля студентов - 36,7\% мужского пола и 43,2\% женского - проводят за монитором больше 2 часов в будние дни. При этом абсолютное большинство лиц женского пола $(42,0 \%)$ в группе с отдельными признаками расстройств адаптации проводит за компьютером около 5 часов в день ежедневно.

Данные таблицы 3 свидетельствует об увеличении средней продолжительности пребывания за компьютером в выходные дни студентами всех 3 групп. Практически половина студентов группы 1 (47,7\% мужского пола и 46,9\% женского) проводят за монитором более $2-\mathrm{x}$ часов в день. В группе 2 большая часть лиц (36,7\% мужского пола и 40\% женского) проводит за монитором примерно 5 часов в день. При этом больше половины студентов женского пола в группе 3 проводят за компьютером около 5 часов в выходные дни.

На следующем этапе изучали взаимосвязь между уровнем психологического дистресса, проявлениями психопатологических симптомов по субшкале соматизации (SOM) среди студентов групп 1,2 и 3 и их увлеченностью компьютером и сетью Интернет (табл. 4., табл. 5.)
Нормальным значением субшкалы SOM яв-

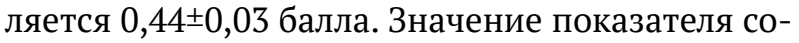
матизации в группе 1 находится в пределах нормы. В группе 2 наблюдается 2-х кратное превышение показателя для лиц как мужского, так и женского пола. Обращает на себя внимание 4-х кратное превышение нормальных значений в группе 3.

Данные значения субшкалы SOM отражают дистресс, возникающий из ощущения соматовегетативной дисфункции.

В группе практически здоровых студентов значение показателя соматизации находится в пределах нормальных значений. Наблюдается 2-х кратное превышение нормы в группе с непатологическими нарушениями адаптации и 4-х кратное превышение в группе с отдельными признаками расстройств адаптации. Соматовегетативная дисфункция при таких значениях субшкалы SOM в группе 2 и 3 проявляется жалобами, фиксированными на кардиоваскулярной, гастроинтестинальной, респираторной и других системах. При этом жалобы студентов 2 группы менее выражены, чем у студентов 3 группы.

Таблица 4.

Взаимосвязь между уровнем выраженности психопатологической симптоматики по субшкале SOM, в баллах (шкала SCL-90-R) и количеством времени, проводимом за компьютером и в сети Интернет (в будние дни)

\begin{tabular}{lcccccc}
\hline \multirow{2}{*}{ Вариант ответа } & \multicolumn{2}{c}{ Группа $1, \mathrm{n}=273$} & \multicolumn{2}{c}{ Группа 2, $\mathrm{n}=155$} & \multicolumn{2}{c}{ Группа 3, $\mathrm{n}=82$} \\
\cline { 2 - 7 } & $\begin{array}{c}\text { женщины, } \\
\mathrm{n}=143\end{array}$ & $\begin{array}{c}\text { мужчины, } \\
\mathrm{n}=130\end{array}$ & $\begin{array}{c}\text { женщины, } \\
\mathrm{n}=95\end{array}$ & $\begin{array}{c}\text { мужчины, } \\
\mathrm{n}=60\end{array}$ & $\begin{array}{c}\text { женщины, } \\
\mathrm{n}=69\end{array}$ & $\begin{array}{c}\text { мужчины, } \\
\mathrm{n}=13\end{array}$ \\
\hline \hline \multirow{2}{*}{ Нисколько } & $0,28 \pm 0,20$ & $0,20 \pm 0,18$ & $0,99 \pm 0,63$ & $0,93 \pm 0,43$ & $1,96 \pm 0,64$ & $2,21 \pm 0,29$ \\
& $(0,0-0,7)$ & $(0,0-0,7)$ & $(0,0-2,4)$ & $(0,4-1,7)$ & $(1,4-3,8)$ & $(2,0-2,4)$ \\
\hline Приблизительно & $0,38 \pm 0,31$ & $0,25 \pm 0,23$ & $0,95 \pm 0,41$ & $0,71 \pm 0,35$ & $2,00 \pm 0,69$ & $1,92 \pm 0,73$ \\
1 -2 часа в день & $(0,0-1,3)$ & $(0,0-0,8)$ & $(0,1-1,7)$ & $(0,1-1,4)$ & $(1,4-3,6)$ & $(0,9-2,8)$ \\
\hline \multirow{2}{*}{ Больше 2-х часов в день } & $0,54 \pm 0,37$ & $0,33 \pm 0,24$ & $0,88 \pm 0,39$ & $0,98 \pm 0,43$ & $1,98 \pm 0,85$ & $2,29 \pm 0,41$ \\
& $(0,0-1,8)$ & $(0,0-1,2)$ & $(0,2-1,9)$ & $(0,0-1,7)$ & $(0,5-3,6)$ & $(2,0-2,6)$ \\
\hline \multirow{2}{*}{ Примерно 5 часов в день } & $0,56 \pm 0,29$ & $0,21 \pm 0,18$ & $1,3 \pm 0,69$ & $0,59 \pm 0,30$ & $1,88 \pm 0,68$ & $1,84 \pm 0,47$ \\
& $(0,0-1,0)$ & $(0,0-0,8)$ & $(0,1-2,8)$ & $(0,1-1,0)$ & $(0,67-3,25)$ & $(1,5-2,2)$ \\
\hline
\end{tabular}


Таблица 5.

Взаимосвязь между уровнем выраженности психопатологической симптоматики по субшкале SOM, в баллах (шкала SCL-90-R) и количеством времени, проводимом за компьютером и в сети Интернет (в выходные дни)

\begin{tabular}{lcccccc}
\hline \multirow{2}{*}{ Вариант ответа } & \multicolumn{2}{c}{ Группа 1, n=273 } & \multicolumn{2}{c}{ Группа 2, n=155 } & \multicolumn{2}{c}{ Группа 3, n=82 } \\
\cline { 2 - 7 } & $\begin{array}{c}\text { женщины, } \\
\mathrm{n}=143\end{array}$ & $\begin{array}{c}\text { мужчины, } \\
\mathrm{n}=130\end{array}$ & $\begin{array}{c}\text { женщины, } \\
\mathrm{n}=95\end{array}$ & $\begin{array}{c}\text { мужчины, } \\
\mathrm{n}=60\end{array}$ & $\begin{array}{c}\text { женщины, } \\
\mathrm{n}=69\end{array}$ & $\begin{array}{c}\text { мужчины, } \\
\mathrm{n}=13\end{array}$ \\
\hline \hline \multirow{2}{*}{ Нисколько } & $0,30 \pm 0,21$ & $0,10 \pm 0,11$ & $0,87 \pm 0,48$ & $0,98 \pm 0,37$ & $1,97 \pm 0,25$ & $2,21 \pm 0,29$ \\
& $(0,0-0,7)$ & $(0,0-0,3)$ & $(0,0-1,4)$ & $(0,7-1,5)$ & $(1,8-2,3)$ & $(2,0-2,4)$ \\
\hline Приблизительно & $0,41 \pm 0,35$ & $0,27 \pm 0,22$ & $0,90 \pm 0,34$ & $0,73 \pm 0,50$ & $1,73 \pm 0,19$ & $2,50 \pm 0,29$ \\
1 -2 часа в день & $(0,0-1,1)$ & $(0,0-0,8)$ & $(0,1-1,5)$ & $(0,0-1,7)$ & $(1,5-2,0)$ & $(2,1-2,8)$ \\
\hline \multirow{2}{*}{ Больше 2-х часов в день } & $0,45 \pm 0,33$ & $0,27 \pm 0,22$ & $0,97 \pm 0,44$ & $0,91 \pm 0,39$ & $2,15 \pm 0,86$ & $1,48 \pm 0,64$ \\
& $(0,0-1,7)$ & $(0,0-0,8)$ & $(0,3-2,4)$ & $(0,3-1,7)$ & $(0,5-3,8)$ & $(0,9-2,1)$ \\
\hline \multirow{2}{*}{ Примерно 5 часов в день } & $0,58 \pm 0,34$ & $0,26 \pm 0,26$ & $1,11 \pm 0,64$ & $0,77 \pm 0,39$ & $1,83 \pm 0,69$ & $2,06 \pm 0,45$ \\
& $(0,0-1,8)$ & $(0,0-1,2)$ & $(0,1-2,8)$ & $(0,1-1,6)$ & $(0,7-3,3)$ & $(1,5-2,6)$ \\
\hline
\end{tabular}

\section{В Ы В 0 Д Ы}

Выявлено, что студенческая молодежь склонна к увлечению компьютерами и сетью Интернет: 23,7\% всех обследованных $(\mathrm{n}=510)$ проводят за компьютером около 5 часов в день ежедневно в будние дни и 33,7\% в выходные дни.

Установлены гендерные особенности склонности молодежи к проведению времени за монитором компьютера и/или в сети Интернет в группах практически здоровых студентов, лиц с ННА и ОПРА.
Определен высокий удельный вес студентов женского пола (42,0\% в будние дни и 50,7\% в выходные дни) с ОПРА, которые проводят за компьютером около 5 часов в день.

Выявлено 2-х кратное превышение нормальных значений показателя соматизации в группе с ННА и 4-х кратное превышение нормы в группе с ОПРА.

Полученные данные легли в основу комплексной программы психопревенции расстройств адаптации и чрезмерного увлечения компьютерами и сетью Интернет у студенческой молодежи.

\section{О.А. Бешуля}

ГОО ВПО «Донецкий национальный медицинский университет имени М. Горького», Донецк

\section{ОСОБЕННОСТИ СОМАТОВЕГЕТАТИВНЫХ ПРОЯВЛЕНИЙ У СТУДЕНЧЕСКОЙ МОЛОДЕЖИ С РАССТРОЙСТВОМ АДАПТАЦИИ, СКЛОННЫХ К УВЛЕЧЕНИЮ КОМПЬЮЕТРАМИ И СЕТЬЮ ИНТЕРНЕТ}

Цель работы: Оценить соматовегетативные проявления у студенческой молодежи с расстройством адаптации, склонной к увлечению компьютерами и сетью Интернет.

Материал и методы. Обследовали 510 студентов мужского и женского пола 1 и 2 курсов одного из университетов в возрасте от 17 до 20 лет. Определяли, какое количество времени студенты проводят в сети Интернет и за компьютером. Для оценки психоэмоционального состояния использовали тест SCL-90-R. Оценивали взаимосвязь количества времени, проводимого в сети Интернет, с уровнем выраженности соматовегетативной симптоматики с использованием субшкалы соматизации (SOM) из опросника SCL90-R.

Результаты и обсуждение. Выраженность психопатологической симптоматики определяли по шкале SCL-90-R. Дизайн исследования предполагал разделение студентов на 3 группы: практически здоровые, с непатологическими нарушениями адаптации (ННА), с отдельными признаками расстройств адаптации (ОПРА). Для этого использовали кластерный анализ методом «k-срединных», с использованием субшкал
SCL-90-R: SOM; INT; DEP; ANX; PHOB. В результате кластерного анализа получили следующие группы студентов: практически здоровые - 273 (53,5\%) студента, среди них 130 (47,6\%) человек мужского пола и $143(52,4 \%)$ - женского; с непатологическими нарушениями адаптации - $155(30,4 \%)$ человек, среди них 60 (38,7\%) лиц мужского пола и 95 (61,3\%) - женского; с отдельными признаками расстройств адаптации - 82 (16,1\%) человека, среди них 13 (15,9\%) мужского пола и $69(84,1 \%)$ - женского.

Выводы. Выявлено, что студенческая молодежь склонна к увлечению компьютерами и сетью Интернет: 23,7\% всех обследованных $(n=510)$ проводят за компьютером около 5 часов в день ежедневно в будние дни и 33,7\% в выходные дни. Установлены гендерные особенности склонности молодежи к проведению времени за монитором компьютера и/или в сети Интернет в группах практически здоровых студентов, лиц с ННА и ОПРА. Определен высокий удельный вес студентов женского пола (42,0\% в будние дни и $50,7 \%$ в выходные дни) с ОПРА, которые проводят за компьютером около 5 часов в день. Выявлено 2-х кратное превышение нормальных значений показа- 
теля соматизации в группе с ННА и 4-х кратное превышение нормы в группе с ОПРА. Полученные данные легли в основу комплексной программы психопревенции расстройств адаптации и чрезмерного увлечения компьютерами и сетью Интернет у студенческой молодежи.

Ключевые слова: студенты, адаптация, SCL-90-R, компьютеры, Интернет

\section{O.A. Beshulia}

SEI HPE «M. Gorky Donetsk National Medical University», Donetsk

\section{FEATURES OF SOMATOVEGETATIVEMANIFESTATIONS OF STUDENT YOUTH WITH AN ADJUSTMENT DISORDER ADDICTED TO COMPUTERS AND THE INTERNET}

Objective: to estimate somatovegetative manifestations of student youth with an adjustment disorder addicted to computers and the Internet.

Materials and methods. 510 male and female students of 1 st and 2 nd courses of one of the universities aged 17 to 20 years were examined. We determined how much time students spend on the Internet and at the computer. To assess the psycho-emotional state we used SCL-90 $-\mathrm{R}$ test. We evaluated relationships between amount of time spent on the Internet and level of somatovegetative symptoms using the somatization subscale (SOM) from the SCL-90-R questionnaire.

Results. Students were divided into 3 groups: practically healthy, with non-pathological adjustment disorders, with individual signs of adjustment disorders. To distribute students into groups, we used cluster analysis (the «k-median» method). We used 5 subscales of SCL-90 -R for dividing students: SOM; INT; DEP; ANX; PHOB. Statistically significant differences were found between students of the following groups: practically healthy 273 (53.5\%) people, among them 130 men (47.6\%) and 143 women (52.4\%); with non-pathological adjustment disorders - 155 (30.4\%) people, among them 60 men
(38.7\%) and 95 women (61.3\%); with individual signs of adjustment disorders - 82 (16.1\%) people, among them 13 people men (15.9\%) and 69 women (84.1\%).

Conclusions. It was revealed that students have an addiction to computers and the Internet: $23.7 \%$ of all surveyed $(\mathrm{n}=510)$ spend about 5 hours a day at the computer every day on weekdays and $33.7 \%$ at the weekend. The gender characteristics of youth inclination to spend time at the computer monitor and / or on the Internet in groups were established.. The high proportion of female students (42.0\% on weekdays and $50.7 \%$ at the weekend) with individual signs of adjustment disorders spend about 5 hours at the computer. 2 -fold excess of normal values of the somatization index in the group with non-pathological adjustment disorders and 4-fold excess of normal values in the group with individual signs of adjustment disorders were revealed. The obtained data formed the basis of a comprehensive programme of psychopreventions of adjustment disorders and excessive enthusiasm for computers and the Internet among student youth.

Key words: students, adjustment, SCL-90-R, computers, the Internet.

\section{ЛИТЕРАТУРА}

1. Шифнер Н.А., Бобров А.Е., Кулыгина М.А. Клиникодинамическая характеристика расстройств адаптации у студентов. Ученые записки СПбГМУ им. акад. И.П. Павлова. 2011; 18 (4): 64-66.

2. Киосева Е.В. Медико-психологическая характеристика и психопревенция адаптационных нарушений у студенческой молодежи (симптоматология, патоперсонология, аддиктивный фон, копинг-стратегии, генодиспозиционная коммуникация): докт. дис. на соискание научной степени д-ра мед. наук. Харьков; 2017. 354.

3. Табачников С.И., Осуховская Е.С. Аддиктивное поведение (игровая аддикция) у школьников и студентов Украины. Архів психіатрії. 2014; 20 (3): 125-126.

4. Жукова М.В., Фролова Е.В., Шишкина К.И. К вопросу о необходимости подготовки будущего педагога к работе по профилатике игровой компьютерной аддикции у дошкольников и младших школьников. Вестник Южно-Уральского государственного гуманитарнопедагогического университета. 2016; 6: 44-51.

5. Москова М.В. Личностные факторы эмоциональной дезадаптации студентов в предэкзаменационный период. Известия Российского государственного педагогического университета им. А.И. Герцена. 2008; 49 : 136-141.

6. Краснова В.В., Холмогорова А.Б. Социальная тревожность и студенческая дезадаптация. Психологическая наука и образование. 2011; 1: 140-150.

\section{REFERENCES}

1. Shifner N.A., Bobrov A.E., Kulygina M.A. Kliniko-dinamicheskaya harakteristika rasstrojstv adaptacii u studentov[Clinical-dynamic characteristic of adaptation disorders in students]. Uchenye zapiski SPbGMU im. akad. I.P. Pavlova. 2011; 18 (4): 64-66. (in Russian).

2. Kioseva E.V. Mediko-psihologicheskaya harakteristika i psihoprevenciya adaptacionnyh narushenij u studencheskoj molodezhi (simptomatologiya, patopersonologiya, addiktivnyj fon, koping-strategii, genodispozicionnaya kommunikaciya) [Medical and psychological characteristic and psychoprevence of adaptation disorders in student youth (symptoms, pathopersonology, addictive background, copying strategies, gene-dispersion communication] : dokt. dis. na soiskanie nauchnoj stepeni d-ra med. nauk. Har'kov; 2017. 354. (in Russian).

3. Tabachnikov S.I., Osuhovskaya E.S. Addiktivnoe povedenie (igrovaya addikciya) u shkol'nikov i studentov Ukrainy [Addictive behavior (game addiction) in schoolchildren and students of Ukraine]. Arhiv psihiatriï. 2014; 20 (3): 125-126. (in Russian).

4. Zhukova M.V., Frolova E.V., Shishkina K.I. K voprosu o neobhodimosti podgotovki budushchego pedagoga $\mathrm{k}$ rabote po profilatike igrovoj komp'yuternoj addikcii $\mathrm{u}$ doshkol'nikov i mladshih shkol'nikov [To the question of the need to prepare the future teacher for work on the profile of game computer adaptation in pre-school and younger schoolchildren]. Vestnik YUzhno-Ural'skogo go- 
7. Краснова В.В., Холмогорова А.Б. Социальная тревожность и суицидальная направленность у студентов. Журнал неврологии и психиатрии им. С.С. Корсакова. 2013; 113 (4): 50-53.

8. Войцех В.Ф., Гальцев Е.В. Нарушение адаптации и суицидальное поведение у молодежи. Социальная и клиническая психиатрия. 2009 ; 19 (2): 17-25.

9. Лещина I.В. Мозгова Т.П. Маркери ризику-антиризику формування розладів адаптації у осіб молодого віку. Укр. вісн. психоневрології. 2015; 23 (2) : 112-113.

10. Мозговая Т.П., Лещина И.В., Федорченко С.В. От лечения расстройств поведения - к охране психического здоровья подростков. Український вісник психоневрології. 2016; 24 (1): 73-75.

11. Опросник выраженности психопатологической сммптоматики = Symptom check list-90-revised - SCL90-R: Адаптация методики Н.В. Тарабриной. - Москва : Институт психологии РАН, лаборатория психологии посттравматического стресса и психотерапии, 2001. 21. sudarstvennogo gumanitarno-pedagogicheskogo universiteta. 2016; 6: 44-51. (in Russian).

5. Moskova M.V. Lichnostnye faktory emocional'noj dezadaptacii studentov v predekzamenacionnyj period [Personal factors of students 'emotional disadaptation in the pre-economic period]. Izvestiya Rossijskogo gosudarstvennogo pedagogicheskogo universiteta im. A. I. Gercena. 2008; 49 : 136-141. (in Russian).

6. Krasnova V.V., Holmogorova A.B. Social'naya trevozhnost' i studencheskaya dezadaptaciya [Social anxiety and student disadaptation]. Psihologicheskaya nauka i obrazovanie. 2011; 1: 140-150. (in Russian).

7. Krasnova V.V., Holmogorova A.B. Social'naya trevozhnost i suicidal'naya napravlennost' u studentov [Social anxiety and suicidal focus in students]. Zhurnal nevrologii i psihiatrii im. C.C. Korsakova. 2013; 113 (4): 50-53. (in Russian).

8. Vojcekh V.F., Gal'cevE.V.Narushenie adaptacii i suicidal'noe povedenie u molodezhi [Adaptation disorder and suicidal behaviour in young people]. Social'naya i klinicheskaya psihiatriya. 2009 ; 19 (2): 17-25. (in Russian).

9. Leshchina, I.V. Mozgova T.P. Markeri riziku-antiriziku formuvannya rozladiv adaptaciï u osib molodogo viku [Risk marker - anti-risk of adaptation disorders in young people]. Ukr. visn. psihonevrologiï. 2015; 23 (2) : 112-113. (in Russian).

10. Mozgovaya T.P., Leshchina I.V., Fedorchenko S.V. Ot lecheniya rasstrojstv povedeniya - $\mathrm{k}$ ohrane psihicheskogo zdorov'ya podrostkov [From treating behavior disorders to protecting adolescent mental health]. Ukraïns'kij visnik psihonevrologiï. 2016; 24 (1): 73-75. (in Russian).

11. Oprosnik vyrazhennosti psihopatologicheskoj smmptomatiki $=$ Symptom check list-90-revised - SCL-90-R: Adaptaciya metodiki N.V. Tarabrinoj. - Moskva : Institut psihologii RAN, laboratoriya psihologii posttravmaticheskogo stressa i psihoterapii, 2001. 21 (in Russian). 